\title{
ChemComm
}

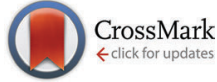

Cite this: Chem. Commun., 2015 51,557

Received 15th October 2014

Accepted 6th November 2014

DOI: $10.1039 / c 4 c c 08174 a$

www.rsc.org/chemcomm

\section{Synthesis of polysubstituted cyclopenta[b]indoles via relay gold(I)/Brønsted acid catalysis $\dagger$}

\author{
Seema Dhiman and S. S. V. Ramasastry*
}

An efficient relay catalytic process involving $\mathrm{Au}(\mathrm{l}) / \mathrm{Br} ø$ nsted acid to access various polysubstituted cyclopentannulated indoles from easily accessible 1-(2-aminophenyl)prop-2-ynols and readily available 1,3-dicarbonyls has been developed. In an unprecedented event, the intermediate 2-indolylmethyl cations undergo the cation-Ene reaction with various 1,3-dicarbonyls followed by an intramolecular FriedelCrafts-type reaction generating functionalized cyclopenta[b]indoles.

Indoles and indolines are considered to be privileged structures due to their widespread occurrence in Nature with intricate structural diversity often associated with impressive bioactivities, and in a pharmaceutical sense due to their drug-like properties. ${ }^{1}$ Among indole derivatives, cyclopenta $[b]$ indoles are especially attractive due to their presence in numerous biologically active natural products, for example, paspalines, terpendoles, emindoles, polyveolines, spiroindimicins, fischerindoles, yuehchukene, etc., in addition to medicinally important compounds such as MK-0524, Fig. 1 . $^{2}$ The presence of complex molecular architectures coupled with impressive pharmacological properties prompted several research groups to contribute

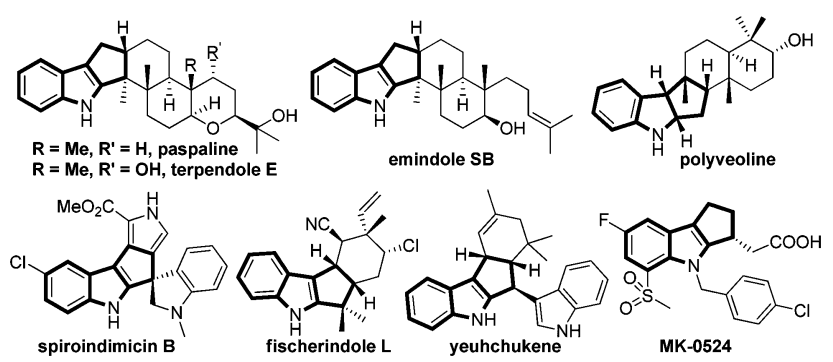

Fig. 1 Representative examples of bioactive cyclopenta[b]indoles.

Department of Chemical Sciences, Indian Institute of Science Education and Research (IISER) Mohali, Sector 81, Manuali PO, S. A. S. Nagar, Punjab 140306, India.E-mail: ramsastry@iisermohali.ac.in

$\dagger$ Electronic supplementary information (ESI) available: Complete experimental procedures and characterization data of all new compounds. CCDC 1029309. For ESI and crystallographic data in CIF or other electronic format see DOI: 10.1039/ c4cc08174a significantly to the construction of cyclopentannulated indole derivatives. ${ }^{3}$ However, the quest for the development of a simple and efficient method to access this class of compounds from readily available starting materials still remains an area of active research.

On the other hand, activation of $\pi$-systems of alkynes and alkenes via gold catalysis for the synthesis of a wide range of natural products and complex molecules in an efficient and predictable manner has received significant attention during the past decade. ${ }^{4}$ Especially, relay catalytic processes involving gold were demonstrated to have great potential to rapidly assemble complex chemical structures often associated with pot, step and atom economy. ${ }^{5}$ Motivated by the pioneering studies by Chan ${ }^{6}$ for the synthesis of indole derivatives starting from propargylic tertalcohols of the type $\mathbf{A}$, and with our experience in the chemistry of heteroaryl carbinols, ${ }^{7}$ we initiated a program to develop an efficient and general methodology towards the synthesis of a novel series of cyclopentannulated indoles and to evaluate their biological efficacy, Scheme 1. Prior to commencing our investigation, a detailed literature survey revealed that the prevailing 2-indolylmethyl cation intermediate $\mathbf{B}$ was routinely trapped by nucleophiles such as alcohols, aryls, heteroaryls, etc. ${ }^{8}$ However, to

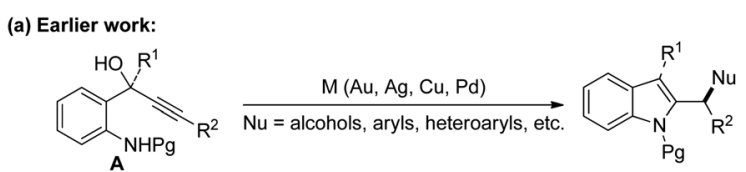

(b) Concept of this work: 1,3-dicarbonyls as nucleophiles and relay $\mathrm{Au}(\mathrm{l}) / \mathrm{Br} ø$ nsted acid catalyzed one-pot domino cyclopentannulation of indoles

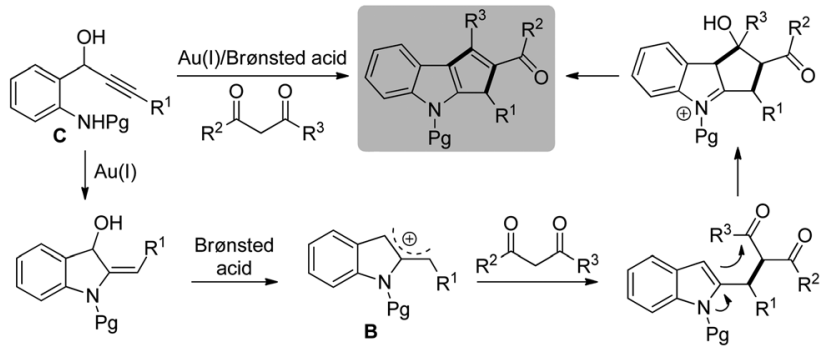

Scheme 1 Our strategy for the synthesis of cyclopentannulated indoles. 
our surprise, no attempt was ever made to employ readily available 1,3-dicarbonyl compounds as nucleophiles. ${ }^{9}$

Herein, we delineate our efforts towards the generation of indolylmethyl cations from 2-aminophenyl propargylic secondary alcohols $\mathbf{C},{ }^{10}$ their reactions with a variety of 1,3-dicarbonyl compounds and subsequent intramolecular aldol-type reactions for the synthesis of 1,2,3-trisubstituted cyclopenta $[b]$ indoles. Accordingly, we initiated optimization studies towards identifying an effective catalytic system and other reaction parameters. For this, amino alcohol $1 \mathbf{a}^{6 b, 11}$ and acetylacetone $2 \mathbf{a}$ were chosen as substrates for the model reaction. The screening results are compiled in Table 1.

To begin with, cyclization of amino alcohol 1a to indoline 3a was explored. The reaction of $1 \mathrm{a}$ in the presence of $\mathrm{Au}(\mathrm{I})$ or $\mathrm{Ag}(\mathrm{I})$ salts alone or a combination of $\mathrm{Au}(\mathrm{I})$ and silver based Lewis acids failed to deliver indoline 3a (Table 1, entries 1-4). Interestingly, amino alcohol 1a generated indoline 3a when a combination of $\mathrm{Au}(\mathrm{I})$ and base was employed; ${ }^{12}$ however, subsequent transformation of indoline $3 \mathbf{a}$ to the desired indole 5a was not observed upon treatment with a variety of Lewis acids, only the acetylacetone adduct $\mathbf{4 a}$ was isolated

Table 1 Optimization of reaction parameters ${ }^{a}$

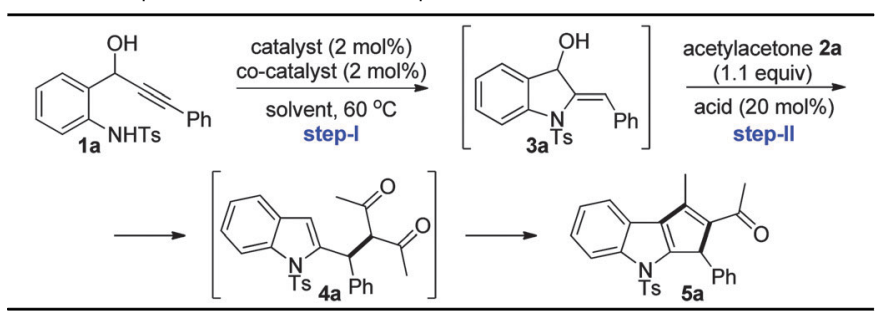

\begin{tabular}{|c|c|c|c|c|c|c|}
\hline Entry & Catalyst & Co-catalyst & Acid & Solvent & $\begin{array}{l}\text { Time } \\
\text { (h) }\end{array}$ & $\begin{array}{l}\text { Yield }^{b} \\
(\%)\end{array}$ \\
\hline 1 & $\mathrm{AuCl}$ & 一 & - & DCE & 48 & - \\
\hline 2 & $\mathrm{PPh}_{3} \mathrm{AuCl}$ & 一 & - & DCE & 48 & - \\
\hline 3 & $\mathrm{AuCl}$ & AgOTf & - & DCE & 48 & - \\
\hline 4 & $\mathrm{PPh}_{3} \mathrm{AuCl}$ & AgOTf & - & DCE & 48 & - \\
\hline $5^{c}$ & $\mathrm{AuCl}$ & $\mathrm{K}_{2} \mathrm{CO}_{3}$ & $\mathrm{Sc}(\mathrm{OTf})_{3}$ & $\mathrm{MeNO}_{2}$ & 48 & - \\
\hline $6^{c}$ & $\mathrm{AuCl}$ & $\mathrm{K}_{2} \mathrm{CO}_{3}$ & $\operatorname{In}(\mathrm{OTf})_{3}$ & $\mathrm{MeNO}_{2}$ & 48 & - \\
\hline $7^{c}$ & $\mathrm{AuCl}$ & $\mathrm{K}_{2} \mathrm{CO}_{3}$ & AgOTf & $\mathrm{MeNO}_{2}$ & 48 & - \\
\hline 8 & $\mathrm{AuCl}$ & $\mathrm{K}_{2} \mathrm{CO}_{3}$ & $\mathrm{Bi}(\mathrm{OTf})_{3}$ & $\mathrm{MeNO}_{2}$ & 26 & 74 \\
\hline 9 & $\mathrm{AuCl}$ & $\mathrm{K}_{2} \mathrm{CO}_{3}$ & TMSOTf & DCE & 20 & 82 \\
\hline 10 & $\mathrm{AuCl}$ & $\mathrm{K}_{2} \mathrm{CO}_{3}$ & TFA & DCE & 13 & - \\
\hline 11 & $\mathrm{AuCl}$ & $\mathrm{K}_{2} \mathrm{CO}_{3}$ & $\mathrm{H}_{3} \mathrm{PO}_{4}$ & DCE & 16 & 51 \\
\hline 12 & $\mathrm{AuCl}$ & $\mathrm{K}_{2} \mathrm{CO}_{3}$ & $\mathrm{HClO}_{4}$ & DCE & 15 & 72 \\
\hline 13 & $\mathrm{AuCl}$ & $\mathrm{K}_{2} \mathrm{CO}_{3}$ & $\mathrm{H}_{2} \mathrm{SO}_{4}$ & DCE & 18 & 70 \\
\hline 14 & $\mathrm{AuCl}$ & $\mathrm{K}_{2} \mathrm{CO}_{3}$ & $\mathrm{TfOH}$ & DCE & 13 & 83 \\
\hline 15 & $\mathrm{AuCl}$ & $\mathrm{K}_{2} \mathrm{CO}_{3}$ & TfOH & $\mathrm{MeNO}_{2}$ & 24 & 74 \\
\hline 16 & $\mathrm{AuCl}$ & $\mathrm{K}_{2} \mathrm{CO}_{3}$ & TfOH & Toluene & 13 & 80 \\
\hline 17 & $\mathrm{AuCl}$ & $\mathrm{NaHCO}_{3}$ & - & DCE & 40 & - \\
\hline 18 & $\mathrm{AuCl}$ & $\mathrm{Na}_{2} \mathrm{CO}_{3}$ & TfOH & DCE & 35 & 53 \\
\hline 19 & $\mathrm{AuCl}$ & $\mathrm{Et}_{3} \mathrm{~N}$ & TfOH & DEC & 27 & 72 \\
\hline $20^{d}$ & AuCl & $\mathrm{K}_{2} \mathrm{CO}_{3}$ & TfOH & DCE & 18 & 90 \\
\hline $21^{c, e}$ & $\mathrm{AuCl}$ & $\mathrm{K}_{2} \mathrm{CO}_{3}$ & $\mathrm{TfOH}$ & DCE & 48 & - \\
\hline $22^{d}$ & $\mathrm{PPh}_{3} \mathrm{AuCl}$ & $\mathrm{K}_{2} \mathrm{CO}_{3}$ & TfOH & DCE & 42 & 76 \\
\hline $23^{d}$ & $\mathrm{AuCl}$ & $\mathrm{K}_{2} \mathrm{CO}_{3}$ & TMSOTf & DCE & 36 & 85 \\
\hline $24^{d}$ & AgOTf & - & TfOH & $\mathrm{MeNO}_{2}$ & 34 & 63 \\
\hline
\end{tabular}

${ }^{a}$ Reaction conditions: a $5 \mathrm{~mL}$ glass vial was filled with $1 \mathrm{a}(0.1 \mathrm{mmol})$, catalyst ( $2 \mathrm{~mol} \%)$, co-catalyst $(2 \mathrm{~mol} \%$ ) in an appropriate solvent $(1 \mathrm{~mL})$ and stirred at $60{ }^{\circ} \mathrm{C}$, upon disappearance of the starting compound (1a), acetylacetone 2a $(0.11 \mathrm{mmol})$ and an acid $(20 \mathrm{~mol} \%)$ were introduced and stirring was continued at $60^{\circ} \mathrm{C}$ until indoline $3 \mathrm{a}$ and acetylacetone adduct 4a disappeared. ${ }^{b}$ Isolated yields after silica gel column chromatography. ${ }^{c}$ Intermediate $3 \mathbf{a}$ formed and only the acetylacetone adduct $4 \mathrm{a}$ was isolated. ${ }^{d} 10 \mathrm{~mol} \% \mathrm{TfOH}$ was employed. ${ }^{e}$ Step-II was carried out at room temperature.
(Table 1, entries 5-7). Nevertheless, an approach for indoline 3a via a catalytic sequence involving $\mathrm{Au}(\mathrm{I})$ and a base could be established for the first time. ${ }^{13}$

Upon further screening, Lewis acids such as Bi(OTf $)_{3}$ and TMSOTf gratifyingly generated the cyclopentannulated indole 5 a in very good yields (Table 1, entries 8 and 9). We were delighted especially because, as per our hypothesis, the intervening indolylmethyl cation formed under Lewis acidic conditions successfully underwent the cation-Ene reaction with acetylacetone $\mathbf{2 a}$, and furthermore the 1,3-dicarbonyl adduct 4a via an intramolecular Friedel-Crafts-type reaction furnished 1,2,3-trisubstituted cyclopenta $[b]$ indole 5a. It is worth mentioning that the current method also constitutes a potential alternative to the traditionally employed methods for indole cyclopentannulations such as [3+2]-cycloadditions, Nazarov cyclizations, etc. ${ }^{14}$ Furthermore, synthesis of cyclopentannulated indoles via 2-indolylmethyl cation intermediates is underexplored. ${ }^{3 h}$

In order to further improve the efficiency of the reaction, we opted to investigate the influence of Brønsted acids in place of Lewis acids in step-II. Among several Brønsted acids explored, trifilic acid mediated reaction in DCE delivered the cyclopentannulated indole 5a in very good yield (Table 1, entries 10-16). Subsequently, influence of the co-catalyst (base) in step-I was also studied. While no desired product was observed when sodium bicarbonate was employed as the co-catalyst, sodium carbonate and an organic base such as triethylamine furnished 5a only in moderate yields (Table 1, entries 17-19). Gratifyingly, further enhancement in the yield was observed when $\mathrm{TfOH}$ loading was reduced from $20 \mathrm{~mol} \%$ to $10 \mathrm{~mol} \%$ (Table 1, entry 20). Striking temperature dependence was realized when the $\mathrm{TfOH}$ reaction at room temperature failed to generate the desired product 5a and only the acetylacetone adduct 4 a was isolated (Table 1, entry 21). Further attempts to enhance the yield were not encouraging (Table 1, entries 22-24).

In order to validate the generality of the unprecedented method for the synthesis of polysubstituted cyclopenta $[b]$ indoles, a variety of 1-(2-aminophenyl)prop-2-ynols $\mathbf{1 a - 1 m}$ were synthesized according to literature methods ${ }^{6,8}$ and subjected to the optimized conditions, Table 2. It is noteworthy that the relay Au(I)/Brønsted acid catalyzed tandem transformation is quite general, and a diverse library of annulated indoles can be rapidly accessed in good to excellent yields (Table 2, 5a-5w). The reaction displays significant tolerance towards various alkynols bearing electrondonating as well as electron-withdrawing aryl groups (for example, $p$-tolyl and $p$-fluorophenyl), heteroaryls such as 2-thienyl, and the alkyl groups. Furthermore, alkyl and aryl-bearing 1,3-diketones, $1,3,5$-triketones, $\beta$-ketoesters and $\beta$-ketoamides are also welltolerated under the reaction conditions.

As can be seen from Table 2, amino alcohol 1a upon reaction with di- and triketones $\mathbf{2 a - 2 d}$, and ketoamide $\mathbf{2 e}$ generated the respective 1,2,3-trisubstituted cyclopentannulated indoles 5a5e in excellent yields. Similarly, the analogous aryl and heteroaryl amino alcohols $\mathbf{1 b}-\mathbf{1 d}$ upon reaction with a variety of diketones, ketoesters and ketoamides generated functionalized cyclopenta $[b]$ indoles (Table 2, 5f-5l). Significantly, reaction of 
Table 2 Substrate scope with 1-(2-aminophenyl)prop-2-ynols and 1,3 -dicarbonyls in the relay Au(I)/Brønsted acid catalyzed tandem process $s^{a, b}$

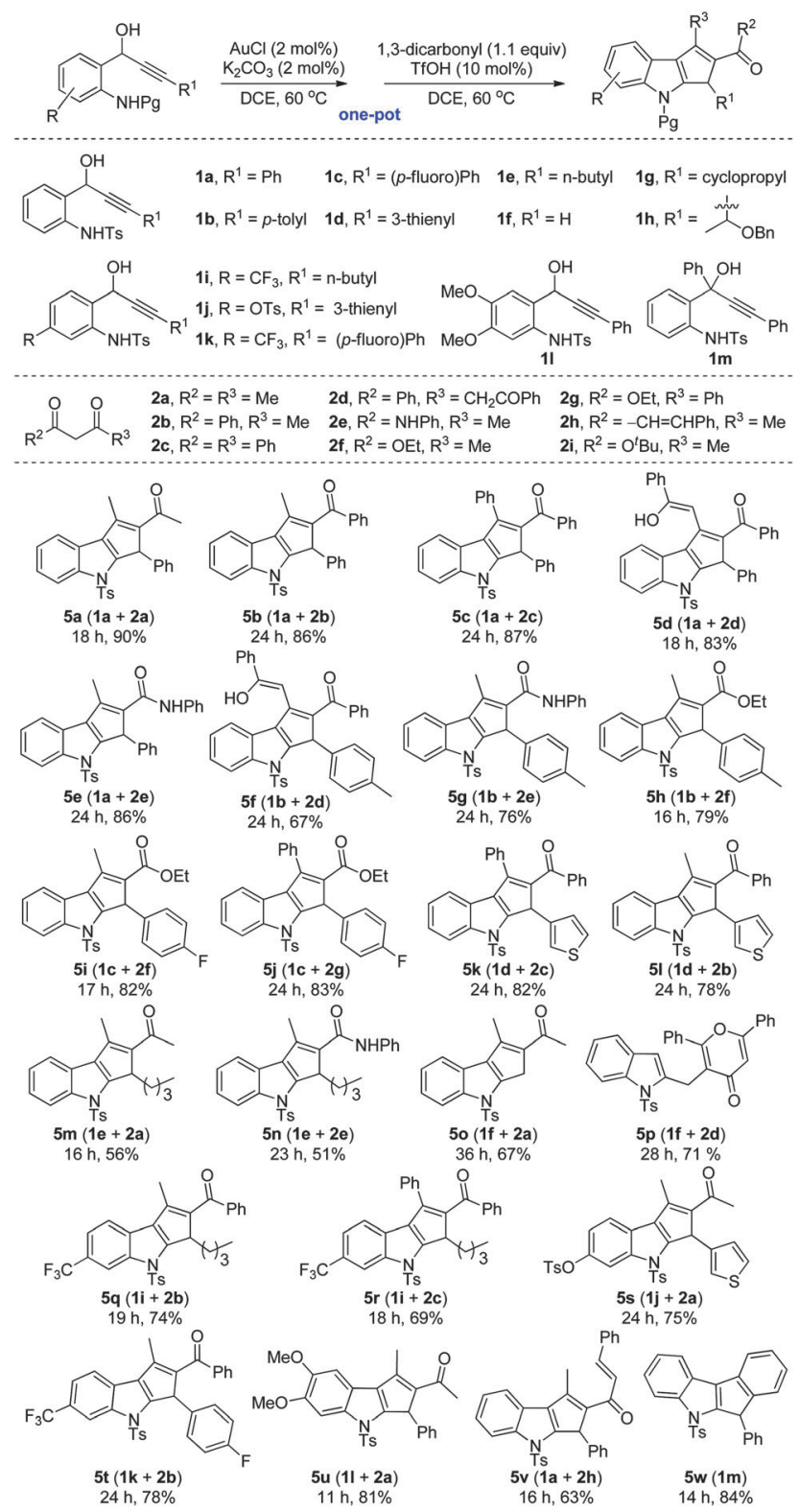

${ }^{a}$ Reaction conditions: a mixture of amino alcohol $1(0.1 \mathrm{mmol}), \mathrm{AuCl}$ ( $2 \mathrm{~mol} \%), \mathrm{K}_{2} \mathrm{CO}_{3}(2 \mathrm{~mol} \%)$ and DCE $(1 \mathrm{~mL})$ in a $5 \mathrm{~mL}$ glass vial was stirred at $60{ }^{\circ} \mathrm{C}$. After complete consumption of the starting compound (1), 1,3-dicarbonyl $2(0.11 \mathrm{mmol})$ and TfOH $(10 \mathrm{~mol} \%)$ were added successively and stirring was continued at $60{ }^{\circ} \mathrm{C}$ until the complete disappearance of the respective 1,3-dicarbonyl adduct $(4) .{ }^{b}$ Isolated yields after silica gel column chromatography.

1e, having a pendent alkyl group on the acetylenic carbon centre, with diketones $2 \mathbf{a}$ and $2 \mathbf{e}$ also furnished the respective annulated indoles $\mathbf{5 m}$ and $\mathbf{5 n}$ though in moderate yields, ${ }^{15}$ but enhanced the scope of this method. Even 1,2-disubstituted cyclopentannulated indoles (such as 5o) could be efficiently generated by the reaction of unsubstituted alkynol 1f with diketone 2a. But reaction of $\mathbf{1 f}$ with triketone $\mathbf{2 d}$, unexpectedly formed the pyranone indole $\mathbf{5 p}$. Complex indole derivatives bearing electron-withdrawing as well as electron-donating substituents (such as $-\mathrm{CF}_{3}$, $-\mathrm{OTs}$, $-\mathrm{OMe}$ ) on the indole moiety could also be accessed easily in high yields (Table $2, \mathbf{5 q}-\mathbf{5 u}$ ). However, contrary to our expectation, the amino alcohols $\mathbf{1 g}$ and $\mathbf{1 h}$ failed to deliver the desired products under the reaction conditions. Presumably, the presence of an acid sensitive cyclopropyl system and a 2-butyne-1,4oxygenated system would have triggered unwanted side reactions. The molecular structure of a representative example $5 \mathbf{v}$, obtained by the reaction of $\mathbf{1 a}$ and $\mathbf{2 h}$, was unambiguously confirmed by single crystal X-ray diffraction analysis (see the ESI $\dagger$ for details). ${ }^{16}$

On the other hand, reaction of amino tert-alcohol $\mathbf{1 m}$ even in the presence of $2 \mathbf{a}$ generated only indole $5 \mathbf{w}$ in $84 \%$ yield via a Nazarov electrocyclization reaction (Table 2). ${ }^{6 a}$ Thus, indoles of the type $5 \mathbf{w}$ could now be accessed in excellent yields with less $\mathrm{Au}(\mathrm{I})$ catalyst loading and under milder reaction conditions over the existing method. ${ }^{6 a}$

Since alcohol 6 and cationic intermediate 7 are believed to be the intermediates in the transformation of $\mathbf{1 a}$ to $\mathbf{5 a}$, we planned to undertake a comparative study between the reactions of amino alcohol 1a and 2-indolyl carbinol 6 under the optimized conditions, Scheme 2. It can be noted that the reaction of amino alcohol 1a with $2 \mathbf{a}$ or $\mathbf{2 e}$ is found to be efficient in generating $5 \mathbf{a}$ or $5 e$, respectively, when compared to the reaction of alcohol 6 in forming $\mathbf{5 a}$ and $\mathbf{5 e}$, thereby clearly demonstrating the advantage of the one-pot tandem process. It is worth mentioning that the direct Friedel-Crafts-type alkylation of unmodified 2-indolyl carbinols and 1,3-dicarbonyls as such is unprecedented ${ }^{17}$ and of course the subsequent cyclization cascade as well.

To further illustrate the generality and synthetic utility of this methodology, we considered an elaboration (see Scheme 3). Thus, reaction of $1 \mathrm{a}$ with ketoester $2 \mathbf{i}$ under the optimized conditions furnished adduct 8, which underwent smooth in situ decarboxylation to form $\beta$-branched 4-(2-indolyl)-2-butanone 9 in $76 \%$ yield, synthesis of which otherwise would require a multistep sequence. Indole 9 upon reaction with excess $\mathrm{Mg}$ in methanol generated alcohol 10 by undergoing simultaneous tosyl deprotection and ketone reduction. Selective $O$-mesylation and subsequent intramolecular $N$-alkylation ${ }^{18}$ conveniently generated 1,3-disubstituted dihydropyrroloindole 11, an important motif prevalent in a number of pharmaceutically important compounds and natural products. ${ }^{19}$

In conclusion, we have developed a general and efficient relay $\mathrm{Au}(\mathrm{I}) / \mathrm{Br} ø$ nsted acid catalyzed one-pot tandem process for the synthesis of medicinally significant 1,2-di- and 1,2,3-trisubstituted cyclopentannulated indoles from 1-(2-aminophenyl)prop-2-ynols

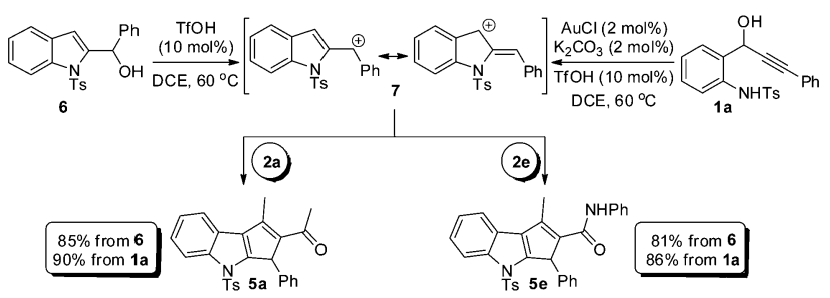

Scheme 2 Comparison between the efficiency of amino alcohol 1a and indolyl carbinol 6 in forming the same end product. First demonstration of a direct reaction between 2 -indolyl carbinols and 1,3-dicarbonyls. 


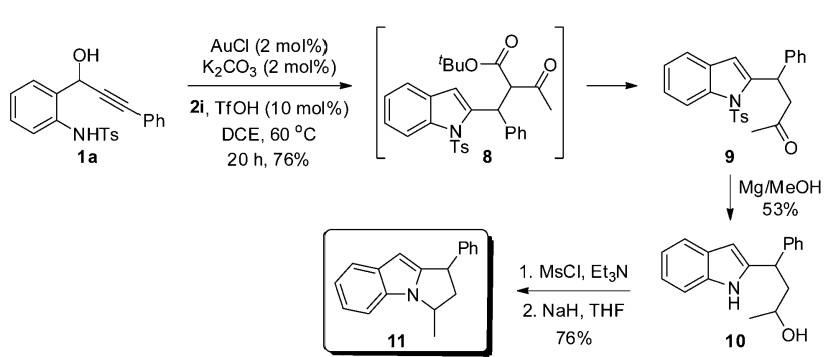

Scheme 3 Elaboration to an advanced intermediate.

and 1,3-dicarbonyls. Key features of this method are its readily accessible starting compounds and atom, step and pot economy. During the course of our investigation, we also developed novel $\mathrm{Au}(\mathrm{I}) / \mathrm{base}$ mediated conditions for the synthesis of indolines starting from 1-(2-aminophenyl)prop-2-ynols. In addition, we have demonstrated for the first time, Friedel-Crafts-type alkylation of unmodified 2-indolyl carbinols and 1,3-dicarbonyls. A study regarding the application of this methodology for the synthesis of biologically active natural products is currently underway in our laboratory and will be communicated shortly.

We are grateful to the DST, Govt of India for financial support through the Fast Track Scheme (SR/FT/CS-156/2011). We thank IISER Mohali for funding and for NMR, mass, and X-ray facilities. S.D. thanks IISER Mohali for a research fellowship.

\section{Notes and references}

1 Some selected reviews: (a) M. Somei and F. Yamada, Nat. Prod. Rep., 2005, 22, 73; (b) T. Kawasaki and K. Higuchi, Nat. Prod. Rep., 2005, 22, 761; (c) S. Cacchi and G. Fabrizi, Chem. Rev., 2005, 105, 2873; (d) K. Higuchi and T. Kawasaki, Nat. Prod. Rep., 2007, 24, 843; (e) V. Sharma, P. Kumar and D. Pathak, J. Heterocycl. Chem., 2010, 47, 491.

2 For paspalines, terpendoles, lolicines, and lolitrems, see: (a) S. C. MundayFinch, A. L. Wilkins and C. O. Miles, J. Agric. Food Chem., 1998, 46, 590; for emindoles, see:; (b) H. Harms, V. Rempel, S. Kehraus, M. Kaiser, P. Hufendiek, C. E. Muller and G. M. Konig, J. Nat. Prod., 2014, 77, 673; for polyveolines, see: (c) I. Ngantchou, B. Nyasse, C. Denier, C. Blonski, V. Hannaert and B. Schneider, Bioorg. Med. Chem. Lett., 2010, 20, 3495; for spiroindimicins, see:; (d) W. Zhang, Z. Liu, S. Li, T. Yang, Q. Zhang, L. Ma, X. Tian, H. Zhang, C. Huang, S. Zhang, J. Ju, Y. Shen and C. Zhang, Org. Lett., 2012, 14, 3364; for fischerindoles, see:; (e) J. M. Richter, Y. Ishihara, T. Masuda, B. W. Whitefield, T. Llamas, A. Pohjakallio and P. S. Baran, J. Am. Chem. Soc., 2008, 130, 17938; for yeuhchukene, see: $(f)$ Y.-C. Kong, K.-F. Cheng, R. C. Cambie and P. G. Waterman, J. Chem. Soc., Chem. Commun., 1986, 47.

3 Some selected references for the synthesis of the cyclopenta $[b]$ indole frameworks, see: (a) C. A. Harrison, R. Leineweber, C. J. Moody and J. M. J. Williams, J. Chem. Soc., Perkin Trans. 1, 1995, 1127; (b) M. Ishikura, Y. Matsuzaki and I. Agata, Chem. Commun., 1996, 2409; (c) E. M. Ferreira and B. M. Stoltz, J. Am. Chem. Soc., 2003, 125, 9578; (d) C. Venkatesh, P. P. Singh, H. Ila and H. Junjappa, Eur. J. Org. Chem., 2006, 5378; (e) K. S. Feldman, M. R. Iyer and D. K. Hester II, Org. Lett., 2006, 8, 3113; $(f)$ M. G. Banwell, X. Ma, R. M. Taylor and A. C. Willis, Org. Lett., 2006, 8, 4959; $(g)$ J. A. Malona, J. M. Colbourne and A. J. Frontier, Org. Lett., 2006, 8, 5661; $(h)$ A. K. Yadav, S. Peruncheralathan, H. Ila and H. Junjappa, J. Org. Chem., 2007, 72, 1388; (i) C. Ferrer, C. H. M. Amijs and A. M. Echavarren, Chem. - Eur. J., 2007, 13, 1358; $(j)$ E. P. Balskus and C. T. Walsh, J. Am. Chem. Soc., 2009, 131, 14648; $(k)$ N.-W. Tseng and M. Lautens, J. Org. Chem., 2009, 74, 1809; (l) F. Churruca, M. Fousteris, Y. Ishikawa, M. von Wantoch Rekowski, C. Hounsou, T. Surrey and A. Giannis, Org. Lett., 2010, 12, 2096; $(m)$ K. Saito, H. Sogou, T. Suga, H. Kusama and N. Iwasawa, J. Am. Chem. Soc., 2011, 133, 689; (n) B. Chen, W. Fan, G. Chai and S. Ma, Org. Lett., 2012, 14, 3616; (o) B. Xu, Z.-L. Guo,
W.-Y. Jin, Z.-P. Wang, Y.-G. Peng and Q.-X. Guo, Angew. Chem., Int. Ed., 2012, 51, 1059.

4 For selected articles on relay gold catalysis, see: (a) G. Dyker, Angew. Chem., Int. Ed., 2000, 39, 4237; (b) G. C. Bond, Catal. Today, 2002, 72, 5; (c) M. Haruta, Nature, 2005, 437, 1098; (d) A. S. K. Hashmi and G. J. Hutchings, Angew. Chem., Int. Ed., 2006, 45, 7896; (e) Z. Li, C. Brouwer and C. He, Chem. Rev., 2008, 108, 3239; $(f)$ A. Arcadi, Chem. Rev., 2008, 108, 3266; ( $g$ ) D. J. Gorin, B. D. Sherry and F. D. Toste, Chem. Rev., 2008, 108, 3351; (h) A. S. K. Hashmi and M. Rudolph, Chem. Soc. Rev., 2008, 37, 1766; (i) A. Furstner, Chem. Soc. Rev., 2009, 38, 3208; (j) M. Bandini, Chem. Soc. Rev., 2011, 40, 1358; (k) D. Qian and J. Zhang, Chem. - Eur. J., 2013, 19, 6984; (l) H. Wu, Y.-P. He and L.-Z. Gong, Org. Lett., 2013, 15, 460; (m) P.-S. Wang, K.-N. Li, X.-L. Zhou, X. Wu, Z.-Y. Han, R. Guo and L.-Z. Gong, Chem. - Eur. J., 2013, 19, 6234; (n) X. Wu, M.-L. Li and P.-S. Wang, J. Org. Chem., 2014, 79, 419; (o) C. Obradorsa and A. M. Echavarren, Chem. Commun., 2014, 50, 16; (p) Y. Horino, Y. Takahashi, Y. Nakashima and H. Abe, RSC Adv., 2014, 4, 6215; (q) S. Nayak, N. Ghosh and A. K. Sahoo, Org. Lett., 2014, 16, 2996.

5 (a) N. T. Patil, V. S. Shinde and B. Gajula, Org. Biomol. Chem., 2012, 10, 211; (b) M. Rueping, J. Dufour and M. S. Maji, Chem. Commun., 2012, 48, 3406.

6 (a) P. Kothandaraman, W. Rao, S. J. Foo and P. W. H. Chan, Angew. Chem., Int. Ed., 2010, 49, 4619; (b) D. Susanti, F. Koh, J. A. Kusuma, P. Kothandaraman and P. W. H. Chan, J. Org. Chem., 2012, 77, 7166; (c) S. R. Mothe, P. Kothandaraman, S. J. L. Lauw, S. M. W. Chin and P. W. H. Chan, Chem. - Eur. J., 2012, 18, 6133.

7 (a) S. Dhiman and S. S. V. Ramasastry, Org. Biomol. Chem., 2013, 11, 4299; (b) S. Dhiman and S. S. V. Ramasastry, Org. Biomol. Chem., 2013, 11, 8030; (c) S. Dhiman and S. S. V. Ramasastry, J. Org. Chem., 2013, 78, 10427; (d) B. Satpathi, S. Dhiman and S. S. V. Ramasastry, Eur. J. Org. Chem., 2014, 2022; (e) S. Kasare, S. K. Bankar and S. S. V. Ramasastry, Org. Lett., 2014, 16, 4284.

8 (a) C. Chowdhury, B. Das, S. Mukherjee and B. Achari, J. Org. Chem., 2012, 77, 5108; (b) N. Thirupathi, M. H. Babu, V. Dwivedi, R. Kant and M. S. Reddy, Org. Lett., 2014, 16, 2908; (c) H. Li, X. Li, H.-Y. Wang, G. N. Winston-McPherson, H.-M. J. Geng, I. A. Guzei and W. Tang, Chem. Commun., 2014, 50, 12293.

9 As such, reactions of 1,3-dicarbonyls and 2-indolylmethyl cations generated by any method were never studied.

10 While reactions of 2-indolylmethyl cations originating from propargylic tertiary alcohols (A) with different nucleophiles are wellestablished, ${ }^{6,8}$ generation of 2-indolylmethyl cations from propargylic secondary alcohols (C) and their reactions with any nucleophile have not been reported so far.

11 Other NH-protecting groups (Ms, Boc, and Ac) were also evaluated prior to proceeding to optimization. Only $N$-sulfonyl propargyl alcohols generated the desired product (see the ESI $\dagger$ for details).

12 Step-I was found to proceed very slowly at room temperature. After several attempts, the reaction temperature was optimized to $60{ }^{\circ} \mathrm{C}$.

13 Earlier, $\mathrm{Au}(\mathrm{I}) /$ Lewis acid, ${ }^{6 a} \mathrm{Ag}(\mathrm{I}),{ }^{6 b} \mathrm{Pd},{ }^{8 a, b} \mathrm{Cu},{ }^{8 c}$ conditions were reported for the conversion of $\mathbf{1}$ to $\mathbf{3}$. For $\mathrm{Au}(\mathrm{I}) /$ base mediated cyclization of 2-(1-hydroxyprop-2-ynyl)phenols to dihydrobenzo-furans, see: H. Harkat, A. Blanc, J.-M. Weibel and P. Pale, J. Org. Chem., 2008, 73, 1620.

14 For [3+2]-cycloadditions, see: (a) I. Kawasaki, M. Terano, A. Kurume, S. Hara, M. Yamashita and S. Ohta, Tetrahedron Lett., 2005, 46, 6549; (b) J. McNulty and D. McLeod, Synlett, 2011, 717; (c) H. Li, R. P. Hughes and J. Wu, J. Am. Chem. Soc., 2014, 136, 6288. Also see: ref. $3 a, d, k$ and $m$. For Nazarov cyclizations, see: (d) J. A. Jordan, G. W. Gribble and J. C. Badenock, Tetrahedron Lett., 2011, 52, 6772. Also see: ref. $3 g$ and $l$.

15 Yield loss in general is attributed to the formation of 2-vinyl- $1 H^{-}$ indoles in case of substrates with a pendent alkyl group on the acetylenic carbon centre. ${ }^{6 a}$

16 CCDC 1029309 has been assigned.

17 For indirect, $\mathrm{S}_{\mathrm{N}} 2$-type reactions, see: (a) M. C. Hillier, J. F. Marcoux, D. L. Zhao, E. J. Grabowski, A. E. McKeown and R. D. Tillyer, J. Org. Chem., 2005, 70, 8385; (b) M. Bandini and A. Eichholzer, Angew. Chem., Int. Ed., 2009, 48, 9533.

18 A. Kuznetsov, A. Makarov, A. E. Rubtsov, A. V. Butin and V. Gevorgyan, J. Org. Chem., 2013, 78, 12144.

19 For pharmaceutically relevant compounds, see: (a) Z. Ding and N. Yoshikai, Angew. Chem., Int. Ed., 2013, 52, 8574; for bioactive natural products, see: (b) D. H. Dethe, R. D. Erande and B. D. Dherange, Org. Lett., 2014, 16, 2764. 